\title{
6
}

\section{Information technology in hypointegrated organizations: communication support versus decision support ${ }^{1}$}

\section{Tommaso Cariati}

Dipartimento di Organizzazione Aziendale, Università della Calabria P.zza Roma, 2 - 87040 Castiglione Cosentino (CS), Italy

Tel. No. +39984442554

\section{Gianpaolo Iazzolino}

Dipartimento di Organizzazione Aziendale, Università della Calabria Via S. Allende, 53 - 87030 Roges di Rende (CS), Italy

Tel. No. + 39984461478

\author{
Anna Tancredi \\ Consultant of Organizational Psychology
}

Via Tribunali, 40 - 87100 Cosenza, Italy

Tel. No. +3998421152

\begin{abstract}
The tumultuous developments of Information Technology and the organizational revolution, beginning in Japan with the Lean Organization concept, where important keywords are autonomy, empowerment etc., changed radically the strategic and operational conditions of companies. The environment was becoming more and more chaotic and, in this context, hypointegrated organizations, characterised by weak structural links and by a dispersed memory where the communication process became the central aspect, emerged.

After discussing the features of the emerging organization forms taking into account the principal theories, our work analyses thoroughly the communication process because
\end{abstract}

\footnotetext{
${ }^{1}$ The research was carried out cooperatively, but in particular Cariati wrote section 1, 5, 6, Iazzolino section 2, Tancredi section 3, 4.
} 
communication has become the co-ordinating and integrating instrument, bound to the ability of using the available media in an effective way.

We suggest organizational criteria for integrating available information technology to implement effective, efficient and reliable information systems to support work, decisions and communication in hypointegrated organizations. According to our model, in a learning organization vision, users should define, with the help of technicians, communication, decision and work support requirements.

In conclusion, we present an application of the proposed information technology integration model: the Urban Regional Co-ordination Planning project, still in progress in Calabria.

\section{Keywords}

Transactional approach, relational theory, learning organization, network enterprise, hypointegrated organization, decision support systems, empowerment, communication process, decision process, information technology, technological network, distributed systems.

\section{INFORMATION TECHNOLOGY AND ORGANIZATIONAL REVOLUTION: BASIC QUESTIONS}

Many contributions in the international debate about Management Information Systems at the beginning of the ' $80 \mathrm{~s}$ pointed out that information technology applications developed in the past neglected the real organizational and decisional processes (Keen, Scott Morton, 1978).

In fact, much of the research work in the area of Decision Support Systems arose from this observation and adopted Simon's framework of problem solving process, and bounded rationality to design more effective Management Information Systems (Simon, 1977). Moreover, authors focused on implementation problems and argued that information system implementation is a process which requires organizational and social change (Keen, Scott Morton, 1978); so, many of them declared one must be careful and prepare adequately for this change, for example through Lewin's three stages of social change: Unfreezing, Moving and Refreezing (Lewin, 1947).

Later, new concepts like Group Decision Support Systems, Office Automation Systems, Computer Based Co-operative Work, etc. came to underline the need of a richer approach than even Decision Support Systems one for successful information technology introduction in organizations.

Some authors (Ciborra, 1984; Cariati et al., 1989) on the basis of the theory of transactional costs (Williamson, 1975, 1979) pointed out that Simon's decisional, cybernetic approach was not adequate to design effective computer based systems in many organizational situations. In particular, they felt the decisional approach neglected the following aspects: (a) in organizations, collective, co-ordinated problem solving rather than individual is important; (b) complexity depends not only on the generic uncertainty (Galbraith, 1977) but also on transaction, exchange uncertainty; (c) a more realistic view of the co-operative work must 
take into account also conflictual, opportunistic human behaviour; (d) an organization is a negotiated order in a network of relationships among actors, operating not necessarily within a hierarchy (Ciborra, 1984; Ouchi, 1980).

While the discussion about what an information system should be or should not be was going on, two phenomena recently changed many things.

First of all, the advancement of information technology has been so rapid that the friendliness of software systems and environments has enabled users to build their own systems tailored to specific needs. So, we have systems based on 4th Generation Languages, on Declarative Languages like Query by Example language or easier ones, on Hypertext and Hypermedia systems built by users themselves, making and refining prototypes that are good, even if they are often not very efficient, nor very reliable.

On the other hand, technicians, having perhaps learned the lesson about systems failures, developed some organizational sensibility and built less naive systems than those built in the past. So, we also have systems designed by engineers based on Object Oriented Languages, on Data Base Management Systems, on Client/Server network architecture that are efficient, reliable and effective enough to provide also Decision Support Systems functions and facilities (Saccà, 1995). Moreover, everybody is aware that communication facilities like Fax, E-mail, Computer Conference Systems, etc. are all very important in present organizations.

The second phenomenon is the revolution in organizational forms. In fact, new competitive requirements, a more dynamic environment, even new information technology have induced important changes in company behaviour. Thus, concepts like Lean Organization (Womack et al., 1990), Network Organization (Miles, Snow, 1996; Thorelli, 1986), Business Process Reengineering (Hammer, 1990), Learning Organization (Nonaka, Johnson, 1985), etc. have emerged. Perhaps now we have good information technology but we do not have organization any more; organization, also because of or thanks to information technology, it is becoming more and more virtual (Davidow, Malone, 1992). But even so organizations continue to be defined through at least three important attributes or dimensions which characterise any company: the economic dimension, the social dimension, and the legal dimension. So researchers have to focus their attention on both the organizational dimension and the other ones.

The transactional cost theory highlighted the crucial question: why does an organization exist? (Williamson, 1975,1979; Ouchi, 1980; Milgrom, Roberts, 1992). Perhaps it is centred too much on a purely economic exchange concept (Migliarese, Ferioli, 1994, 1995) and neglects symbolic interpersonal transactions which always take place in any social interaction, as pointed out by psychologists, linguists and educators (Watzlawick et al., 1967; Bruner, 1986), but it provides a paradigm for understanding many present innovative organizational forms. But now we probably need a more powerful framework to explain every complex organizational phenomenon; this framework may be defined by the integration of different paradigms that till now have operated separately, such as the transactional, relational (Ferioli, 1994; Migliarese, Ferioli, 1995), linguistic, and others.

Returning to Decision Support Systems, in the early '80s their conceptual scheme included a Data Base, an adequate User Interface and, to underline the importance of suitable data processing models, a Model Base (Keen, Scott Morton, 1978). But in time it has evolved 
significantly to incorporate a Knowledge Base, an Expert System and, lastly, a Text Base "for providing not only quantitative but also qualitative information to the decision makers" (Hwang et al., 1995); see Figure 1.

We ask: is it really necessary to point out in a paper written for this purpose that text handling in Decision Support Systems is important too? Did not Hypertext Systems stress this need for any Management Information Systems at least from mid '80s (Conklin, 1987), with this term coined in the late '60s (Nelson, 1967)?.

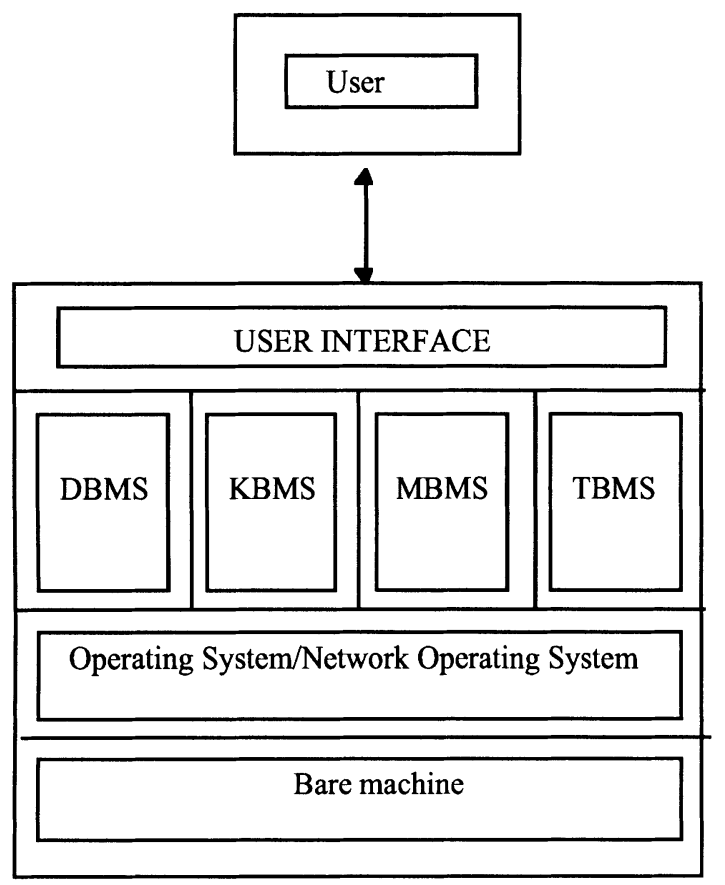

Figure 1 DSS conceptual scheme

However, the crucial question, even after so much work has been done, is still: have we understood properly the decisional process, especially when it takes place in the new organizational forms? Many problems are still open, such as:

1. Actors preferences are developed dynamically during problem resolution and during processes of interpretation construction, not before (March, 1987).

2. Rules come normally to code historical experiences that otherwise can not be made useful (March, Olsen, 1976).

3. Ambiguous problems are often better solved through exploratory resolution methods, not through quantitative models (Lindblom, 1959). 
4. The meaning of a message, a problem, a symptom is defined through evocative exploration of the deep structure of the language (March, 1987).

5. Maybe we do not have to make decisions but just to wait for solutions to come to us (Harrigel, 1975).

Paradoxically these problems are particularly important in current virtual, magmatic, hypointegrated, quasi-market/quasi-clan (Ouchi, 1980) organizational forms.

Nevertheless, the discussion and the research work must go on. But one day perhaps we will find out that the really important question is: why do people enter organizations? Then the answer may be too complex and too simple at the same time... an ontological answer: people enter organizations because, they unconsciously hope, organized work permits them to go beyond space and time. But when we find this out, we will be able to say with Pessoa: "One day, when time is finished, our lives will meet again, but free from Places and Names".

\section{FEATURES OF EMERGING HYPOINTEGRATED ORGANIZATIONS}

The principal causes of the process of change that have been noted in the last decade show a wide-spread instability due to internal and external turbulence of organizations, and also to the rapid acceleration of change.

In order to be able to move within such a complex and heterogeneous context, some researchers consider it useful to refer to the theories based on chaos, which are becoming more and more popular even in study of management.

The main challenge in a firm is to generate competitive advantages within chaotic conditions of discontinuity, even by modifying the organization.

The change that seems relevant to the above aim is in the learning ability of the organization, this means the flexibility and the ability to continuously review strategic choices and to give attention to all signals especially those coming from the external environment (Nonaka, Johnson, 1985).

In order to create an environment oriented towards action learning, it is necessary to act on: the forms of management behaviour, going beyond the concept of uniformity, but evaluating the differences and disagreements, and the forms of relationships at the interpersonal and interfunctional level, by paying attention to real relationships between people and groups, leaving behind those tools of integration which seem too structured and procedural (Miggiani, Scilletta, 1992).

The element of "disorder" in the organization may be important and in some cases it's necessary to include it in the planning phase, in order to develop a system in which there is overflowing information, activities and management responsibilities (Nonaka, 1991). In fact, only in this way we can have the creation of common schemes and languages with major effectiveness in communication and in the distribution of information.

As an example, we might underline the difference between handbooks about organization existing in western companies, USA and Europe, and those existing in Japanese Companies (Nonaka, Johnson, 1985): while operating handbooks in the western world prescribe activities 
and responsibilities in detail, in Japan they focus on behaviour and values, and training is left to managers and to their ability to transmit competence and motivation and also to stimulate continuous improvements (Womack et al., 1990).

Learning is generated not only by internal relations, but also by the external ones and such relations are not only related to buying and selling, but also to "co-operation in generating/acquiring knowledge" (Miggiani, Scilletta, 1992).

The network enterprise, which any pushes organization towards learning and therefore towards innovation, is the suitable answer to the turbulence and instability of the environment. The model of the structured firm is characterised by stability in relations. Here the behaviour produces the structure, and vice-versa: the structure generates the behaviour but this also takes on a corrective value for structural evolution (Pilotti, 1990).

The elements that remain invariable are the rules which define the process of coproduction: such rules take on the connotation of linguistic-communicative rules and in this context the new information technology assumes a central role.

The network enterprise doesn't have a permanent strategic and operating centre: it is changeable and determined from time to time according to the strategy adopted.

The term network enterprise, or network of companies, or organizational network indicates different classes of organizational forms. One class concerns the processes of activity decentralisation towards firms that are sub-suppliers. A second class concerns the enterprises connected to a particular area, for example the called "industrial districts" or "scientific and technological parks". A third type seems to be formed by associations - the Confederation of Agriculture, production co-operatives, or by special contract agreements.

However, a tendency that is worth underlining is the fact that many big companies organise themselves internally into independent units, i.e. business units, teams, project groups on the border of market and hierarchy.

This process of weakening structural connections produces new organizational forms, that we call hypointegrated.

These organizational forms present problems of control and observation because their memory is dispersed and their parts are connected in a very weak relations network, similarly with the territorial systems (Ciborra et al., 1977; Ciborra et al., 1982).

This leads to the need for an efficient co-ordination of the activities of all single sub-units, and also for some variables that have become essential for competitiveness: (a) the globalization, which brings the need of finding a compromise between a unitary management and an adequate perception of local situations; (b) the need to reduce the "time to market", which requires a better integration between functional units; (c) the necessity of better service to client; (d) the need to control and reduce costs.

The main problem of hypointegrated organizational forms is not decision support, but communication support, which has also important implications for individual or group decisions.

Of course, information technology has a key role for its capacity of co-ordinating different levels and different sub-units, connecting people of one organization or between different organizations (Rockart, Short, 1989). 


\section{COMMUNICATION SUPPORT VERSUS DECISION SUPPORT}

In the past researchers' attention was directed mostly to the problem solving aspects, especially on individual levels, this was due to organizational models that used to concentrate the decision power in specific subjects, inside some organizations and arranged in certain hierarchic levels.

Decisions have been, and sometimes still are, characteristics of high level and intermediate management and the importance of the decisions then corresponds to the recognised power of a decision maker.

One of the models of problem solving maintains that during the process detailed instructions are carried out at an unconscious state, like computer programs, that organise in a sequence the complex myriad of information contained in our mind.

The decisional process is highlighted as a way of reacting to problems. In fact, in this process there are not only logical and analytic components that can run by means of analytical instruments, but also creativity, critical judgement and general ability that can be called "intuition".

Many researchers lead in the attempt to create operative models that can be used in practice and Lang, Dittrich and White (1978) gave us a wide review.

An important aspect in the decisional processes is that which examines the nature of the problem; this problem can be considered as a deviation from the rule - problem in its strict sense - or as a research into the best choice for the future.

In the first case, it deals with correcting or eliminating an undesired effect, in the second we face undefined situations, free from any exact solution, but rather with many possible results characterised by a different level of pleasure of the decision maker. It is this second aspect that characterises the actual corporate problems.

Faced with these questions, traditional schemes and structures seem to be old-fashioned, while other organizational forms develop solutions by co-operative activities.

The processes that become active in this case aren't analytical or quantitative, but holistic and qualitative and are based on the relation and communication ability of the same group.

The decision support or group decision support systems must demonstrate the capacity to integrate actively in the managerial decision process and to integrate actively in the group. This means we should elaborate models, valid for the different knowledge approaches that characterise the different decision makers.

Thus, the internal events require an adequate strategy of inference, for example the construction of a model. Whoever creates the model must mention explicitly the rules linking the sub-units (Kleinmuntz, 1966).

In the decisional process it is necessary to have at one's disposal information that, because of nature and complexity, will never be complete and exact. It is therefore necessary to have a correct definition of the information needed and an efficient data acquisition.

This data are necessary for the production/elaboration of products and services, distributed in the field and not located in the office. 
The information requirements are often not well defined and therefore there is an information overload or it becomes unusable. Information requirements must consider opportunity, punctuality, availability and comprehensibility.

In fact, these characteristics are rarely found, especially in weak structures or in professional working groups, whose components can be also very distant geographically or structurally.

In these cases, the decisions belong to the group and have effects not only on the vertical structure, but mostly on a number of "cells" of collateral work, that can be defined as a group of persons whose energies are directed to common objectives, that operate well together, harmoniously and with good results (Francis, Young 1979).

These cells can be composed of people with different skills and coming from various working, geographic, cultural backgrounds, usually without formal leadership.

The use of technology must allow people to meet with unlimited time, place or presence, realising, when necessary, a sort of permanent meeting.

It is important to point out the emergence of new concepts of "space" and "information/product", when space isn't only real, but virtual, because of information technology. The information/product must have in this virtual space different representations; it is necessary therefore to articulate the information as "public", "shared" or "private".

As an example, we mention the demonstration system DICUN (Distributed International Communications Using Networks - 1990) which was developed in the ambit of the European RACE project to study international interactions of a groupware between different multimedia workstations. It shows that the interpersonal relation between the components of those virtual groups seem to become friendly and that the groups seem to be steadily "oriented towards work".

During the realisation of a new product/service, we note in these groups the constitution of "cells" of independent work from the traditional hierarchy, with an acceleration of useful exchanges.

In fact hypointegrated organizations are often made by actors having equal power and the same rights and generate "bossless" organizational situations.

\section{THE COMMUNICATION PROCESS IN BOSSLESS SITUATIONS}

It has become necessary to develop the interfunctional collaboration, operating deeply on the mechanisms that establish the connective tissue of the firm (Milana, 1991).

While the control systems and management by objective are fundamental instruments to orient, value and control the firm's and the individual's actions and results, the internal communication plays an important role in supporting and diffusing the culture of the service and the total quality and information systems can facilitate notably the intersection.

In fact, the structure of company communication models can influence, by it self, the way of being and behaving in terms of safety, responsibility and independence. The same structure can also influence the way of operating of a group in terms of speed, exactness and adaptability. 
If we consider two schemes of communication as in Figure 2, where the arrows represent bi-directional communications, we notice how the star scheme shows the presence of a leader that determines and manages the transactions. It is therefore an autocratic organization where the decisional power is concentrated in the hands of one subject. The circular scheme instead is typical of an open and democratic organization, where the whole group participates in the decisions, because communication between the subjects is free to flow in every direction.

It seems also that the models of communication of this type are more functional in the introduction and consolidation of the firm transformation phases (Bavelas, Strauss, 1962) and that co-operation is the best way of managing hypointegrated situations (Greiner, 1972).

It is evident, then, how the ability to establish efficient interpersonal relations and therefore to develop effective communication transaction is the critical knot of the new organization forms. In fact communication services create the "nervous tissue" of the firm.

As regards this, in a communication process, not only the "text" but the following four aspects are fundamental (Kjolseth, 1972):

1. the background knowledge, i.e. the knowledge people possess;

2. the foreground knowledge, i.e. the knowledge of the communication rules regarding different situations;

3. the emergent grounds, i.e. specific rules necessary during communication process;

4. the transcendent grounds, i.e. what determines the bounds of relevance in a specific situation.

It is well worth underlining that communication is more or less important in every organizational situation: in the bossless ones, however, it assumes a central role in coordinating and integrating activities and also in the decision making process that becomes collaborative.
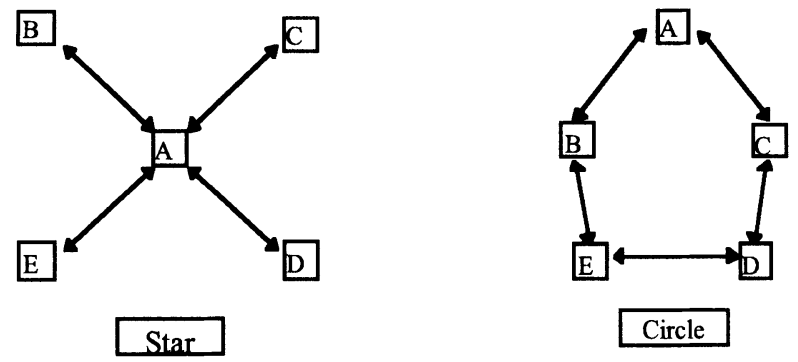

Figure 2 Two schemes of communicational process 


\section{CRITERIA FOR USING AVAILABLE INFORMATION TECHNOLOGY}

After considering the central role of the communication process in emerging organization forms, especially in the hypointegrated and bossless ones, we'll focus our attention on the importance of using the available information technology in an effective way.

We'll suggest organizational criteria for the implementation of effective, efficient and reliable information systems to support work, decisions and communication.

The dream of software systems designers remains interoperability, i.e. the possibility to integrate in one system different devices, processors, Operating Systems, software platforms, application packages, etc.

Waiting for this dream to become reality, maybe across the realisation of a software portable layer integrator, that works as interface between basic platforms such as operating systems, Database Management Systems, etc. and external application packages - hoping it isn't a "Waiting for Godot" - we must integrate what is available on the market in the best possible way.

In the market, besides powerful and sophisticated operating systems and network operating systems, we have Hypertext Systems, productivity tools and Project Management systems; enhanced database management systems, even multimedia or multidimensional, whose technology is already mature; packages of Product Data Management and Engineering Document Management, Work Flow Management systems, middleware for the development of applications centred on firm processes; all these software systems are waiting to become appropriately integrated.

The integration of instruments and environments can happen on a work flow management platform that permits a co-ordination of information and people engaged in work groups. Work flow management systems that rely on special relational databases embedded in developing environments, possibly object oriented, give a first answer to problems of interfunctional integration by means of the vault, a common database system where data, documents, etc. are stored and managed as in Figure 3.

The integration of the virtual organizational parts can be based on a technological infrastructure client/server to which it is easy and possible to join, even temporarily with a portable personal computer, possibly extracted from a special chassis.

The nodes of technological infrastructure don't coincide with the organization units or people, i.e. with the nodes of the organizational network; they are only doors, entrance points to the network. The technological infrastructure is a hyper-network where it is possible to define many different organizational networks.

Every project group, team, task force, etc., in which empowerment is one of the most important keywords, must define the requirements of the technological system it wants to use. The users, in a learning organization perspective, must take the initiative and define their needs in terms of information, decision support, communication, external interface, connection to network functionalities. 


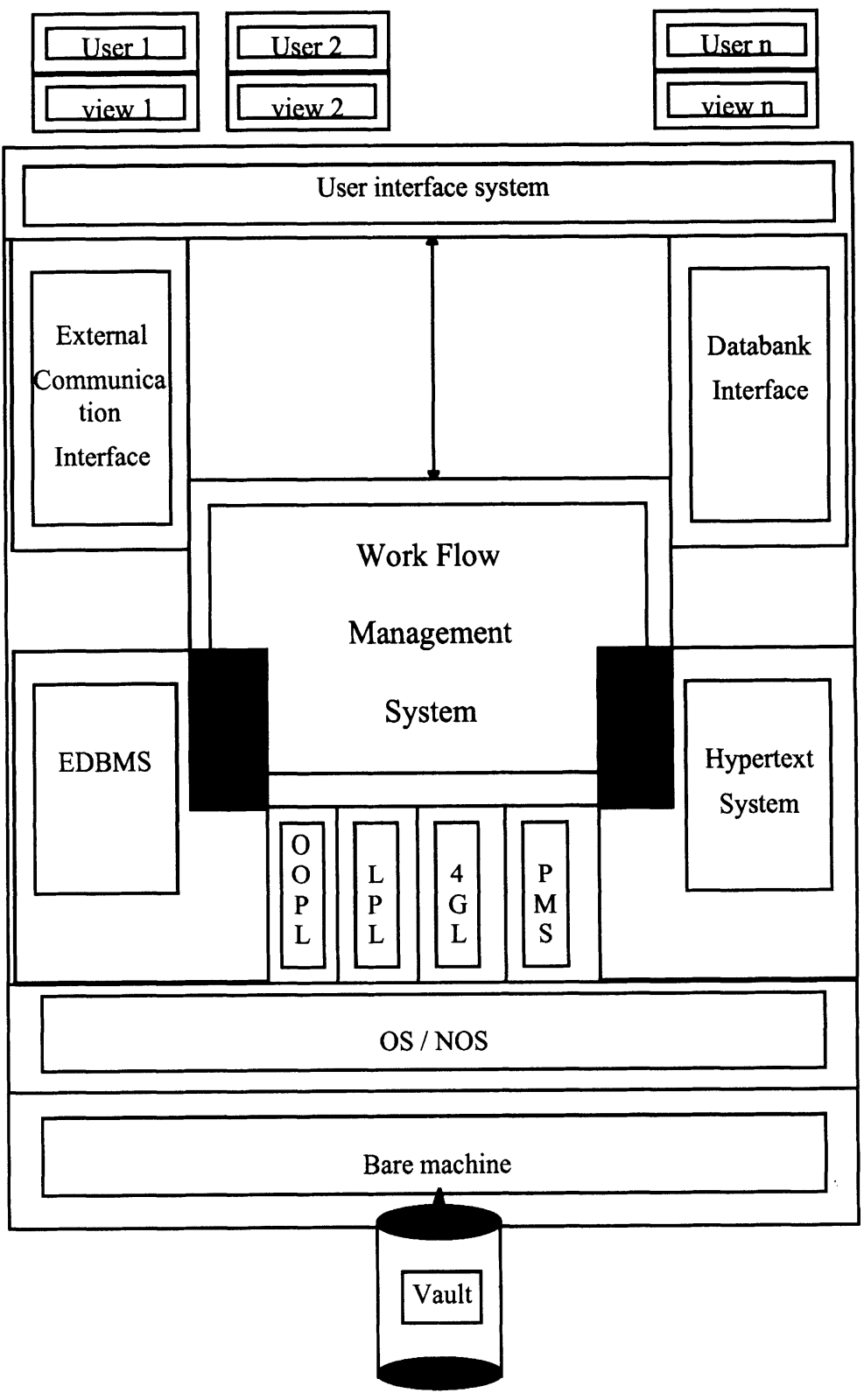

Figure 3 Information Technology integration model 
In this phase the users must be helped, according to the dimensions of the group, from one or more information technology-organizational consultants, coming from management information systems unit or function. These consultants operate similarly to the maintenance employees and have a particular professional skill: they have good knowledge of computer science and a certain sensibility for business and organization problems.

The first thing to be done is to define correctly the nodes of the organization network single person or group or organizational unit - and the relations between these nodes. This work has to be done co-operatively and will be defined across an hypertext software system: on the relative hyper-graph nodes, relations, functions, tasks, working instruments will be defined. A copy of this organizational model could be installed in every node of the technological network which corresponds to a node of the organizational network.

Much attention must be dedicated to system security and reliability, even though the importance of this problem differs from case to case. In particular, we must consider the problems of data integrity and consistency; they must be treated carefully in the definition of the data scheme and in the analysis of the redundancies (Date, 1986). The problem is particularly critical when data are distributed. In this case, in order to avoid too many data transfers and too many break downs and recovery of the system for the execution of complex protocols, it is worth making some duplicate copies of data in different sites. In this way, if a place has all the data it needs, the only transfer of data necessary is when we must carry out remote updates.

Other technical problems regard the incorrectness of data that happens when we have the execution of concurrent transactions and when we have the failure of the system; these problems must be administrated with accurate lock and unlock clause, with special log transactions and adequate recovery protocols. Finally we have problems that stem from

the distribution of transactions, these must be managed with two phase commitment protocols (Ullman, 1982).

Moreover in the distribution of data the problem of location of fragments of relations in different nodes of the network becomes critical. An accurate assignment of horizontal fragments - only some lines - or vertical fragments - only some columns - can reduce significantly the transfer of data from one node to another of the network. It is always possible to reform data across ordinary or special SQL clauses like union, intersect, except, not in, join.

\section{INFORMATION TECHNOLOGY IN A PLANNING PROJECT}

To realise the urban regional co-ordination plan of Calabria, the most southern region of the Italian peninsula, a working group formed by many skilled people who operate in the Universities of Cosenza and Reggio Calabria was established. This working group identified the first instrument of co-ordination in the regional periodic conferences which were attended by the interested parties, even only as suppliers or users of the information of the plan. The territory is an hypointegrated system so the plan and the planning process required particular attitude from the operators involved. 
The working group was divided into subgroups formed by interdependent units that require continuous information exchange, besides a support for the decisions or for projection, such as Geographical Information Systems, Computer Aided Design systems, etc.

The information system design, conceived together with the project group, proposed to use information technology as communication, co-ordination, decision support for users, information sources and project groups, in the phase of realisation of the plan as well as in the phase of putting the plan into operation. The information system project examined three principal aspects (Cariati et al., 1993): (a) definition of the technological infrastructure hardware, software and communication networks - necessary to collect, store and communicate information; (b) definition of the organizational structure in terms of behaviour, resources, tasks, competencies, responsibilities for efficient management of the technological infrastructure and the information; (c) definition of standards, methodology, and instruments that make sure the information system doesn't become, once the plan becomes reality, a "cathedral in the desert".

For this purpose we proposed a guide scheme that consists of an "informative contract" among people that operate in the region and are therefore interested in the project as information users or suppliers; this was to avoid obsolescence and inconsistency of the managed information, which is the principal resource of the system.

As regards the technological infrastructures, technicians together with main users realised a system based on three principal nodes, located near the three principal centres involved in the planning processes and in the realisation of the plan itself, i.e. the "Office of Plan", University of Calabria and University of Reggio Calabria.

To these three principal points all those people involved in the plan and those interested in the information system must be connected, for example institutions - Chamber of Commerce, Professional Associations, etc. - as users and as information sources. The emerging system is a computer network providing also sectorial data banks created on the base of the information collected or produced by the system, to which the extemporaneous users of the system will derive, i.e. those users not directly involved in the planning work or in the realisation process of the plan.

The principal nodes of the system have a general structure that includes:

1. Multimedia database that organises in a unique conceptual scheme all the information regarding the region and the plan;

2. Information sources interfaces across which the system acquires the information coming from the area;

3. User interfaces and work support tools across which the users retrieve information from the system and submit elaboration, simulations, evaluations, etc. Among these we have:

- interface to data-banks from extemporaneous users;

- plan user interface;

- decision support environment;

- work support tools;

4. Management module for the information system. 


\section{CONCLUSIONS}

In this research we started by considering the dynamic and changeable nature of modern companies in the face of environmental turbulence.

In fact, the environment was becoming more and more chaotic and, in this context, hypointegrated organizations, characterised by weak structural links and by a dispersed memory where the communication process becomes the central aspect, emerged.

After discussing the peculiarities of the emerging organization forms, even taking into account the principal theories, our work analyses the communication process because communication becomes the co-ordinating and integrating instrument, bound to the ability of using the available media in an effective way.

We have suggested organizational criteria for integrating available information technologies to implement effective, efficient and reliable systems to support work, decisions and communication in hypointegrated organizations. According to our model, in a learning organization vision, users should define, with the help of technicians, communication, decision and work support requirements.

Finally, we presented an application of the proposed information technology integration model: the Urban Regional Co-ordination Planning project, an ongoing project in Calabria.

Further developments of this research would be: (a) the definition of an interpretation theory of the new organization forms that seem to have the characteristic of hypointegration, that is able to integrate relational, transactional, linguistic-communication approaches that usually operated independently; (b) the realisation of applications of the information technology integration model in different organizational context to test its validity further; (c) the definition of a training model for users to also develop the appropriate response to organizational needs.

\section{REFERENCES}

Bavelas, A. and Strauss G. (1962) Group Dynamics and Intergroup Relations, in The Planning of Change (eds K. Benne and R. Chin), New York, Holt, Rinehart \& Winston.

Bruner, J. (1986) Actual Minds, Possible Worlds. Harvard Univ. Press, Cambridge, Mass.

Cariati, T. and , G. and Saccà, D. (1993) Sistema Informativo per il Piano di Coordinamento Regionale della Calabria, in Report at the Regional Government.

Cariati, T. and Ciborra, C. and Maggiolini, P. (1989) Office Information Systems Planning: the Transactional Perspective, in Organization and Information Systems (eds Z. Kaltuekar, J. Gricar), Bled, Slovenia.

Carta, G. (1989) Innovazione e Cambiamento Organizzativo. L'Impresa, 4, 78-84.

Ciborra, C. (1984) Management Information Systems: a Contractual View, in Beyond Productivity: Information Systems Development for Organizational Effectiveness (ed Th.M.A. Bemelmans), North-Holland, Amsterdam.

Ciborra, C. (1989) Tecnologie di coordinamento. Franco Angeli, Milano. 
Ciborra, C. and Gasbarri, G. and Maggiolini, P. (1977) Systèmes d'information et systèmes d'organisation hypointégrés. Modelisation et maîtrise des systèmes. Editions hommes et techniques, Paris.

Ciborra, C. and Maggiolini, P. and Migliarese, P. (1982) Regional Information Systems: Alternative Models and Design Strategies, in Evolutionary Information Systems (ed. J. Hawgood), North Holland, Amsterdam.

Conklin, J. (1987) Hypertext: an Introduction and Survey. IEEE Computer, September 1987.

Date, C.J. (1986) Introduction to Database Systems. Addison Wesley, Reading, Mass.

Davidow, W.H. and Malone, M.S. (1992) The virtual corporation. Harper Business, New York.

Ferioli, C. (1994) La relazione come modello di legami nelle reti organizzative interne, in Le relazioni interorganizzative, Workshop AiIG, Bologna.

Francis, D. and Young, D. (1979) Improving work groups; a practical manual for team building. University Associates, San Diego, California.

Galbraith, J.R. (1977) Designing Complex Organizations. Addison Wesley, Reading, Mass.

Greiner, L.E. (1972) Evolution and Revolution as Organizations Grow. Harvard Business Review, July-August, 37-46.

Hammer, M. (1990) Re-engineering Work: Don't Automate, Obliterate. Harvard Business Review.

Herrigel, E. (1975) Lo Zen e il tiro con l'arco. Adelphi, Milano.

Hersey, P. and Blancherd, K. (1982) Management of Organizational Behavior. Prentice-Hall Inc., Englewood Cliffs, N.J.

Hwang, C. and Conlon, S. and Gillenwater, E. (1995) Incorporating a Text Base into Decision Support Systems. (not yet published report).

Keen, P.G. and Scott Morton, M.S. (1978) Decision Support Systems: an Organizational Perspective. Addison Wesley, Reading Mass.

Kjolseth, R. (1972) Making Sense: Natural Language and Shared Knowledge in Understanding, in Advances in the Sociology of Language (ed. J. Fishman) The Hague, Mouton.

Kleinmuntz, B. (1966) Problem Solving: Research, Method and Theory. John Wiley \& Sons, New York.

Lang, J.R. and Dittrich, J. and White, S. (1978) Managerial problem solving models: a review and a proposal. Academy of Management Review, October.

Lewin, K. (1947) Group Decision and Social Change, in Readings in Social Psychology (eds T.M. Newcomb and E.L. Hartley), Holt, New Jersey.

Lindblom, C.E. (1959) The Science of Modelling Through. Public Administration Review.

March, J.G. and Olsen, J.P. (1976) The uncertainty of the Past: Organizational Learn Under Ambiguity. European Journal of Political Research.

March, J.G. (1987) Ambiguity and Accounting: the Elusive Link between Information and Decision Making. Accounting, Organization and Society.

Miggiani, F. and Scilletta, V. (1992) Progettare l'apprendimento organizzativo. Sviluppo \& Organizzazione, 133, Set/Ott. 
Migliarese, P. and Ferioli, C. (1995) Strumenti organizzativi ed informatici di collaborazione nell'impresa innovativa, in Organizzazione, risorse umane, e processi innovativi nello sviluppo del sistema delle imprese, Workshop AiIG, Torino.

Milana, P. (1991) Service management e interfunzionalità. Harvard Espansione, 52, settembre, 89-96.

Miles, R. and Snow, C. (1986) Network Organizations: New Concepts for New Forms. California Management Review.

Milgrom, P. and Roberts, J. (1992) Economics, Organization and Management, Prentice Hall Inc., New Jersey.

Nelson, T.H. (1967) Getting it out of our System, in Information Retrieval: A Critical Review (ed. Schechter), Thompson Books, Wash.

Nonaka, I. (1991) The knowledge-creating company. Harvard Business Review.

Nonaka, I. and Johnson, J. K. (1985) Organizational learning in Japanese companies. California Management Review.

Ouchi, W.G. (1980) Markets, Bureaucracies and Clans. Administrative Science Quarterly, October 1980.

Pilotti, L. (1990) Dall'impresa-struttura all'impresa-progetto: dalle transazioni ai linguaggi nelle forme di impresa a rete. Economia e politica industriale, 65.

Rockart, J. F. and Short, J. E. (1989) It in the 1990s: Managing Organizational Interdependence. Sloan Management Review, Winter.

Saccà, D. (1995) Sistemi evoluti di basi di dati. Franco Angeli, Milano.

Simon, H.A. (1977) The new Science of Management Decision. Prentice Hall, New Jersey.

Thorelli, H. (1986) Networks: between markets and hierarchies. Strategic Management Journal.

Ullman, J.D. (1982) Principles of Database Systems. Computer Science Press Inc.

Watzlawick, P. and Blavin, J.H. and Jackson, D.D. (1967) Pragmatic of Human Communication. W.W. Norton \& Co, New York.

Williamson, O.E. (1979) Transactional-cost Economics: the Governance of Contractual Relations. Journal of Law and Economics, October 1979.

Williamson, O.E. (1975) Markets and Hierarchies: Analysis and Antitrust Implications. The Free Press, New York.

Womack, J.P. and Jones, D.T. and Roos, D. (1990) The Machine that Changed the World. Rawson. 


\section{BIOGRAPHY}

Tomasso Cariati graduated in Management Engineering from University of Calabria, Italy, in 1984. Later he attended a post graduate course of Software Engineering and started to carry out research in Management Information Systems and Organizational Systems, areas in which he is currently involved. He also worked as a consultant for several companies. At present he is lecturer of Economics and Management in the Faculty of Engineering at the University of Calabria, Italy.

Gianpaolo Iazzolino graduated in Management Engineering in 1993. Since graduating he has continued his research into new forms of organization, both internal and external, and their link with innovation processes. He has taught in the Engineering faculty of the University of Calabria. He is currently involved in a research project, "Innovative organizational models", in the Department of Business Organization.

Anna Tancredi has a degree in psychology from the University of Roma. At present she is working as an educational consultant for several companies. She has also participated in designing educational multimedia products. 